\title{
The South African Surgical Outcomes Study: A 7-day prospective observational cohort study
}

\author{
B M Biccard, ${ }^{1} \mathrm{PhD}$; T E Madiba, ${ }^{2} \mathrm{PhD}$; on behalf of the South African Surgical Outcomes Study investigators \\ ${ }^{1}$ Discipline of Anaesthesiology and Critical Care, School of Clinical Medicine, College of Health Sciences, Nelson R Mandela \\ School of Medicine, University of KwaZulu-Natal, Durban, South Africa \\ ${ }_{2}^{2}$ Department of Surgery, School of Clinical Medicine, College of Health Sciences, Nelson R Mandela School of Medicine, \\ University of KwaZulu-Natal, Durban, South Africa
}

Corresponding author: B Biccard (biccardb@ukzn.ac.za)

\begin{abstract}
Background. Non-cardiac surgical morbidity and mortality is a major global public health burden. Sub-Saharan African perioperative outcome data are scarce. South Africa (SA) faces a unique public health challenge, engulfed as it is by four simultaneous epidemics: $(i)$ poverty-related diseases; (ii) non-communicable diseases; (iii) HIV and related diseases; and (iv) injury and violence. Understanding the effects of these epidemics on perioperative outcomes may provide an important perspective on the surgical health of the country.

Objectives. To investigate the perioperative mortality and need for critical care admission in patients undergoing inpatient non-cardiac surgery in SA.

Methods. A 7-day national, multicentre, prospective, observational cohort study of all patients $\geq 16$ years of age undergoing inpatient noncardiac surgery between 19 and 26 May 2014 at 50 public sector, government-funded hospitals in SA.

Results. The study included $3927 / 4021$ eligible patients (97.7\%) recruited, with 45/50 hospitals (90.0\%) submitting data that described all eligible patients. Crude in-hospital mortality was 123/3 927 (3.1\%; 95\% confidence interval (CI) 2.6 - 3.7). The rate of postoperative admission to critical care units was $255 / 3927$ (6.5\%; $95 \%$ CI $5.7-7.3$ ), with $43.5 \%$ of admissions being unplanned. Of the surgical procedures 2 120/3 915 (54.2\%) were urgent or emergency ones, with a population-attributable risk for mortality of $25.5 \%$ (95\% CI 5.1 55.8 ) and a risk of admission to critical care of $23.7 \%$ (95\% CI 4.7 - 51.4).

Conclusions. Most patients in SA's public sector hospitals undergo urgent and emergency surgery, which is strongly associated with mortality and unplanned critical care admissions. Non-communicable diseases have a larger proportional contribution to mortality than infections and injuries. However, the most common comorbidity, HIV infection, was not associated with in-hospital mortality. The study was registered on ClinicalTrials.gov (NCT02141867).
\end{abstract}

S Afr Med J 2015;105(6):465-475. DOI:10.7196/SAMJ.9435

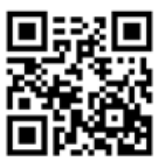

Non-cardiac surgery represents a major global public health burden, ${ }^{[1]}$ with a postoperative mortality rate of $2-4 \% \cdot{ }^{[2,3]}$ Surgery is cost-effective, however, ${ }^{[4]}$ and a core component of health. ${ }^{[5]}$ Surgical outcomes were well described in Europe in the European Surgical Outcomes Study (EuSOS). ${ }^{[3]}$ These data cannot be extrapolated to South Africa (SA), as the country has a lower human development index than Europe and different population morbidity patterns. SA faces four simultaneous major epidemics: $(i)$ poverty-related diseases; (ii) non-communicable diseases (NCDs); (iii) HIV and related diseases; and (iv) injury and violence. ${ }^{[6]}$ In SA, perioperative outcome data are scarce. ${ }^{[7]}$ The Global Burden of Disease Study ${ }^{[8]}$ suggests a proportionally larger contribution of communicable diseases to perioperative mortality compared with Europe, and a lesser contribution of NCDs. The contribution of HIV to perioperative outcomes is unclear. ${ }^{[9]}$

The above provided the rationale to conduct a study similar to EuSOS in SA, known as the South African Surgical Outcomes Study (SASOS). The primary outcome was in-hospital mortality. Secondary outcomes included duration of hospital stay, rate of admission to critical care following surgery, and duration of critical care stay. In order to understand the proportional contribution of communicable diseases, NCDs and injuries to surgical outcomes, these variables were also added to the adopted EuSOS dataset. Risk factors associated with in-hospital mortality and critical care admissions were also explored.

\section{Methods}

This was a 7-day, SA national multicentre prospective observational cohort study of patients aged $\geq 16$ years undergoing inpatient noncardiac surgery. The study was registered on ClinicalTrials.gov (NCT02141867).

Departments of anaesthesia, surgery, critical care and gynaecology affiliated to all the medical schools in SA agreed to participate. A sample of 50 participating hospitals was obtained by approaching all the hospitals in which training by these academic departments took place. Additional hospitals were recruited through professional contacts. All SA provinces were represented. Hospital-specific data were collected, including number of operating rooms and number and level of critical care beds. Ethics approval was obtained for all sites.

The ethics review board of each medical school (University of Cape Town, University of the Free State, University of KwaZuluNatal, University of Limpopo, University of Pretoria, Stellenbosch University, University of the Witwatersrand (Wits) and Walter Sisulu University) approved the study. For the majority of sites, a waiver of consent was approved. Wits and the Free State Provincial Administration stipulated that informed consent be required from all patients, with deferred consent for patients who could not give consent prior to surgery. Wits stipulated that only patients aged $\geq 18$ years could consent to participate. The intention was to recruit all eligible patients in order to minimise data selection bias. 
Recruitment ran from $07 \mathrm{~h} 00$ on 19 May 2014 to $06 \mathrm{~h} 59$ on 26 May. Eligible patients included all patients aged $\geq 16$ years (with the exception of the Wits hospitals) undergoing elective or non-elective inpatient noncardiac surgery during the 7-day recruitment period. Exclusions were planned day surgery, cardiac surgery, radiological procedures not requiring anaesthesia, and obstetric patients. Recruitment preoperatively, and follow-up until discharge, were performed by local investigators. The study was censored at 30 days postoperatively for patients still in hospital.

The EuSOS dataset was adopted with minor changes. The major deviation from the EuSOS protocol, as recommended by the EuSOS steering committee, was to censor the study at 30 days as opposed to 60 days because most of the deaths in EuSOS occurred within 30 days of surgery.

The same potential risk factors as in EuSOS were collected for in-hospital mortality and critical care mortality, but the primary indication for surgery, based on the categories of communicable diseases, NCDs and injuries, was added. Neurosurgical patients were included. To ensure consistency in data definitions and interpretation, the principal investigators (BMB and TEM) made site visits to meet with local investigators and provide study educational material. The website provided educational support and a regularly updated 'frequently asked questions' web page. The case report forms (CRFs) are available on the study website (www.sasos.co.za).

Data were collected on paper CRFs and were pseudoanonymised by unique numerical codes generated during data transcription onto an internet-based CRF. Each patient could only be identified on the electronic CRF by their numerical code. The co-ordinating study team could not trace data back to an individual patient without contact with the local team. Access to the data entry system was username and password protected. All electronic data transfer was encrypted using a secure protocol. The study was reported according to the STROBE statement. ${ }^{[10]}$

\section{Statistical analysis}

Based on expected surgical volumes submitted to the steering committee from the participating hospitals, we believed that it would be possible to generate a sample size close to 7500 patients during a 7 -day recruitment period. We assumed the same mortality rate as that for EuSOS $(4 \%)^{[3]}$ and an admission rate to critical care of half that in $\operatorname{EuSOS~(4\% ~v.~} 8 \%$, respectively). ${ }^{[3]}$ We could therefore include up to 30 variables in logistical regression models for mortality and critical care admission. ${ }^{[11]}$ The data collected were all part of routine clinical care. Categorical variables were described as proportions and compared using $\chi^{2}$ tests, Fisher's exact tests, Pearson's $\chi^{2}$ tests or $\chi^{2}$ tests with Yates's correction, as appropriate. Continuous variables were described as means and standard deviations (SDs) if normally distributed, or otherwise as medians and interquartile ranges (IQRs). Comparisons of continuous variables between groups were performed using unpaired $t$-tests or one-way analysis of variance, as appropriate. Univariate analysis was performed to test for risk factors associated with critical care admission and/ or in-hospital death.

Generalised linear mixed models using a logit link were used to identify independent risk factors for binary outcomes. These included one-level, hierarchical two-level and three-level models to account for the expected correlation in outcomes within hospitals and provinces. We used a threelevel generalised mixed model, with patients being at the first level, hospital at the second and province at the third. We excluded patients with missing values for potential risk predictors, and only used complete case analysis as $<4 \%$ of the dataset was incomplete for a potential clinical risk predictor. ${ }^{[12]}$ Results were reported as adjusted odds ratios (ORs) with 95\% confidence intervals (CIs). All factors with a univariate association of $p<0.05$ were entered into the models. The exception was diabetes, which was not entered into the mortality model because we identified confounding between diabetes, American Society of Anesthesiologists (ASA) category and age. In the critical care admission regression, as nine of the 14 surgical categories had univariate associations with critical care admission, we entered a single surgical categorical variable into the regression. The average population-attributable risk (PAR) for variables associated with the outcomes was calculated ${ }^{[13]}$ for a singlelevel model. Univariate and multivariate statistical analyses were performed using Statistical Package for the Social Sciences (SPSS) version 21 (SPSS Inc., USA). R statistical software package version 3.0.2 ( $\mathrm{R}$ Foundation for Statistical Computing, Austria) was used to compute the PARs. All contingency table comparisons and unpaired $t$-tests between SASOS and EuSOS data were conducted using GraphPad Software Online Calculators (Graphpad Software Inc., USA).

\section{Results}

SASOS included 50 government-funded hospitals: 8 district hospitals, 41 regional or tertiary hospitals and 1 specialised services hospital. These hospitals had a median of 5 (IQR 4 - 8) operating rooms. Critical care units were available in 44/50 hospitals $(88.0 \%)$. These units provided a median of 7 (IQR 4 -16) critical care beds, with a median of 6 (IQR 2 - 10) beds with access to mechanical ventilation and 3 (IQR 0 - 6) without mechanical ventilation.

The study recruitment is shown in the flow diagram in Fig. 1. The overall recruitment was $3927 / 4021$ of eligible patients (97.7\%), with $45 / 50$ hospitals

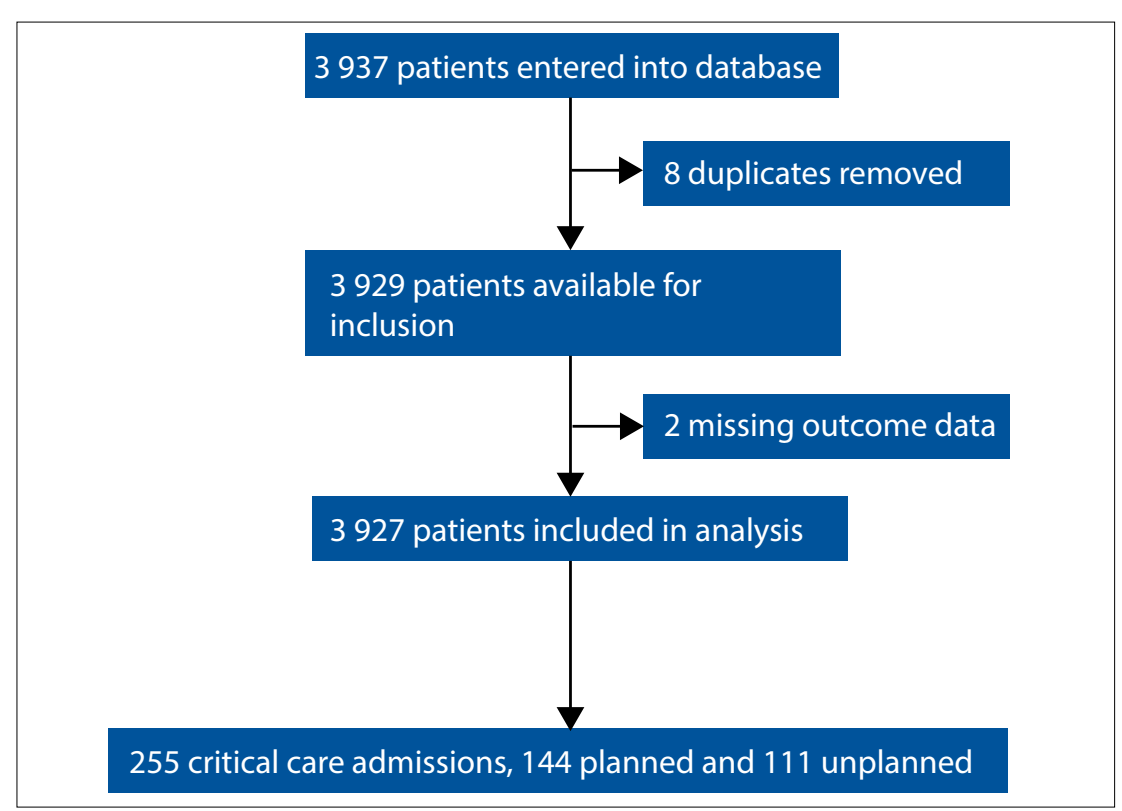

Fig. 1. CONSORT diagram for survival analysis and critical care admission. 
Table 1. Description of cohort ${ }^{\star}$

\begin{tabular}{|c|c|c|c|c|c|}
\hline & $\begin{array}{l}\text { All patients } \\
(N=3927)\end{array}$ & $\begin{array}{l}\text { Alive } \\
(N=3 \text { 804) }\end{array}$ & $\begin{array}{l}\text { Died } \\
(N=123)\end{array}$ & OR $(95 \% \mathrm{CI})$ & $p$-value \\
\hline Age (years), mean (SD) & $43.5(17.6)$ & $43.3(17.6)$ & $52.1(17.7)$ & $1.03(1.02-1.04)$ & $<0.001$ \\
\hline Male, $n(\%)$ & $1994(50.8)$ & $1923(50.6)$ & $71(57.7)$ & $1.33(0.93-1.2)$ & 0.12 \\
\hline Current smoker, $n(\%)$ & $1083(28.2)$ & $1057(28.4)$ & $26(23.0)$ & $0.75(0.48-1.12)$ & 0.21 \\
\hline \multicolumn{6}{|l|}{ ASA category, $n(\%)$} \\
\hline 1 & $1743(44.7)$ & $1731(45.8)$ & $12(9.8)$ & Reference & \\
\hline 2 & $1347(34.6)$ & $1318(34.9)$ & $29(23.8)$ & $3.18(1.61-6.24)$ & $<0.001$ \\
\hline 3 & $663(17.0)$ & $623(16.5)$ & $40(32.8)$ & $9.26(4.83-17.77)$ & $<0.001$ \\
\hline 4 & $131(3.4)$ & $94(2.5)$ & $37(30.3)$ & $56.78(28.67-112.46)$ & $<0.001$ \\
\hline 5 & $14(0.4)$ & $10(0.3)$ & $4(3.3)$ & $57.70(15.87-209.84)$ & $<0.001$ \\
\hline \multicolumn{6}{|l|}{ Grade of surgery, $n(\%)$} \\
\hline Minor & $1403(36.1)$ & $1387(36.8)$ & $16(13.2)$ & Reference & \\
\hline Intermediate & $1672(43.0)$ & $1627(43.2)$ & $45(37.2)$ & $2.40(1.35-4.26)$ & 0.003 \\
\hline Major & $810(20.8)$ & $750(19.9)$ & $60(49.6)$ & $6.94(3.97-6.94)$ & $<0.001$ \\
\hline \multicolumn{6}{|l|}{ Urgency of surgery, $n(\%)$} \\
\hline Elective & $1795(45.8)$ & $1770(46.7)$ & $25(20.3)$ & Reference & \\
\hline Urgent & $1290(33.0)$ & $1248(32.9)$ & $42(34.1)$ & $2.38(1.45-3.93)$ & 0.001 \\
\hline Emergency & $830(21.2)$ & $774(20.4)$ & $56(45.5)$ & $5.12(3.17-8.27)$ & $<0.001$ \\
\hline Laparoscopic surgery, $n(\%)$ & $159(4.1)$ & $159(4.2)$ & $0(0.0)$ & & 0.01 \\
\hline \multicolumn{6}{|l|}{ Surgical specialty, $n(\%)$} \\
\hline Orthopaedic & $1112(28.4)$ & $1100(29.0)$ & $12(9.8)$ & $0.22(0.11-0.45)$ & $<0.001$ \\
\hline Breast & $109(2.8)$ & $108(2.8)$ & $1(0.8)$ & $0.19(0.03-1.41)$ & 0.10 \\
\hline Gynaecology & $525(13.4)$ & $523(13.8)$ & $2(1.6)$ & $0.08(0.02-0.33)$ & 0.001 \\
\hline Vascular & $134(3.4)$ & $125(3.3)$ & $9(7.3)$ & $1.47(0.67-3.24)$ & 0.34 \\
\hline Upper GIT & $154(3.9)$ & $136(3.6)$ & $18(14.6)$ & $2.70(1.42-5.11)$ & 0.002 \\
\hline Lower GIT & $400(10.2)$ & $376(9.9)$ & $24(19.5)$ & $1.30(0.73-2.33)$ & 0.38 \\
\hline Hepatobiliary & $88(2.2)$ & $84(2.2)$ & $4(3.3)$ & $0.97(0.33-2.87)$ & 0.96 \\
\hline Plastics & $242(6.2)$ & $235(6.2)$ & $7(5.7)$ & $0.61(0.26-1.43)$ & 0.25 \\
\hline Urology & $212(5.4)$ & $208(5.5)$ & $4(3.3)$ & $0.39(0.13-1.14)$ & 0.25 \\
\hline Kidney & $13(0.3)$ & $13(0.3)$ & $0(0.0)$ & & 0.52 \\
\hline Head and neck & $222(5.7)$ & $216(5.7)$ & $6(4.9)$ & $0.57(0.23-1.40)$ & 0.22 \\
\hline Neurosurgery & $133(3.4)$ & $122(3.2)$ & $11(8.9)$ & $1.84(0.88-3.85)$ & 0.11 \\
\hline Thoracic & $65(1.7)$ & $64(1.7)$ & $1(0.8)$ & $0.32(0.04-2.39)$ & 0.32 \\
\hline Other & $513(13.1)$ & $489(12.9)$ & $24(19.5)$ & Reference & \\
\hline \multicolumn{6}{|l|}{ Primary indication for surgery, $n(\%)$} \\
\hline Non-communicable & $1881(48.1)$ & $1832(48.3)$ & $49(39.8)$ & Reference & \\
\hline Injury & $1297(33.1)$ & $1253(33.1)$ & $44(35.8)$ & $1.31(0.87-1.99)$ & 0.29 \\
\hline Infective & $736(18.8)$ & $706(18.6)$ & $30(24.4)$ & $1.59(1.00-2.52)$ & 0.05 \\
\hline \multicolumn{6}{|l|}{ Comorbid disorder, $n(\%)$} \\
\hline Coronary artery disease & $160(4.1)$ & $152(4.1)$ & $8(6.7)$ & $1.71(0.82-3.56)$ & 0.16 \\
\hline Congestive heart failure & $55(1.4)$ & $52(1.4)$ & $3(2.5)$ & $1.84(0.57-5.98)$ & 0.31 \\
\hline Diabetes mellitus (no insulin) & $225(5.8)$ & $217(5.8)$ & $8(6.7)$ & $1.18(0.57-2.44)$ & 0.67 \\
\hline Diabetes mellitus with insulin therapy & $171(4.4)$ & $160(4.3)$ & $11(9.2)$ & $2.29(1.21-4.34)$ & 0.01 \\
\hline Metastatic cancer & $101(2.6)$ & $89(2.4)$ & $12(10.1)$ & $4.61(2.45-8.69)$ & $<0.001$ \\
\hline Cirrhosis & $7(0.2)$ & $6(0.2)$ & $1(0.8)$ & $5.29(0.63-44.27)$ & 0.12 \\
\hline Stroke or TIA & $55(1.4)$ & $47(1.3)$ & $8(6.7)$ & $5.68(2.62-12.30)$ & $<0.001$ \\
\hline COPD/asthma & $240(6.2)$ & $230(6.1)$ & $10(8.4)$ & $1.40(0.73-2.72)$ & 0.31 \\
\hline HIV-positive/AIDS & $509(13.2)$ & $498(13.3)$ & $11(9.2)$ & $0.67(0.36-1.25)$ & 0.67 \\
\hline
\end{tabular}


(90.0\%) submitting data on all eligible patients. The patient characteristics and univariate associations with in-hospital mortality are shown in Table 1 . Of the patients, $131 / 3927$ (3.3\%) had missing clinical risk predictor data for in-hospital mortality.

The in-hospital mortality rate was 123/3 927 (3.1\%; 95\% CI 2.6 - 3.7). There were no deaths at the district hospitals $(0 / 255)$ and $122 / 3624$ deaths (3.1\%; 95\% CI 2.5 - 3.7) at the regional and tertiary hospitals. The highest hospital mortality was $9.5 \%$. The median duration of hospital stay was 3 days (IQR $1-6$ ). The rate of postoperative admission to critical care was $255 / 3927$ (6.5\%; $95 \%$ CI $5.7-7.3)$, with $144 / 3927$ (3.7\%; 95\% CI 3.1 - 4.3) admissions planned and 111/3 927 (2.8\%; 95\% CI 2.3 - 3.3) unplanned; 111/255 (43.5\%) critical care admissions were unplanned. More patients were admitted to critical care in the regional and tertiary hospitals $(248 / 3625,6.8 \%)$ than in the district hospitals (7/255, 2.7\%; $p=0.008)$. Sixty-six of the patients who died (53.7\%) were not admitted to critical care. Critical care mortality was 57/255 (22.4\%). Patients who had unplanned admissions to critical care had a significantly higher mortality than those with planned admissions (37/111 (33.3\%) v. 20/144 (13.9\%), respectively; $p<0.001$ ) (Fig. 2). The median duration of critical care stay was 3 days (IQR 1 - 7). The generalised linear model for in-hospital mortality and the associated PAR for independent risk factors are shown in Table 2.

The univariate associations with critical care admissions are shown in Table 3. Of the patients, 132/3 927 (3.4\%) had missing clinical risk predictor data for critical care admission. The generalised linear model for critical care admission and the associated PAR for independent risk factors are shown in Table 4.

Comparisons between the SASOS data and the EuSOS data ${ }^{[3]}$ are shown in Table 5. The mortalities were not compared as the outcome durations were different, and we could not risk-adjust for the differences in comorbidities between the populations.

\section{Discussion \\ Principal findings}

The SASOS in-hospital mortality was 3.1\%, with $6.5 \%$ of surgical patients having been admitted to a critical care unit. The median duration of hospital stay was 3 days (IQR 1 - 6) and that of critical care 3 days (IQR 1 7). Most surgery was urgent or emergency (2 120/3 915, 66.4\%). Urgent and emergency surgery represented a significant PAR for

Table 2. Three-level generalised linear model for in-hospital mortality

\begin{tabular}{|c|c|c|c|}
\hline & $\mathrm{OR}^{\star}(95 \% \mathrm{CI})$ & $p$-value & $\begin{array}{l}\text { One-level PAR } \\
\%(95 \% \mathrm{CI})\end{array}$ \\
\hline Age (years) & $1.02(1.01-1.04)$ & 0.001 & NS \\
\hline \multicolumn{4}{|l|}{ ASA category } \\
\hline 1 & Reference & & $39.3(12.4-77.1)$ \\
\hline 2 & $2.95(1.41-6.17)$ & 0.004 & \\
\hline 3 & $5.18(2.48-10.86)$ & $<0.001$ & \\
\hline 4 & $22.09(9.87-49.46)$ & $<0.001$ & \\
\hline 5 & $15.51(3.43-70.25)$ & $<0.001$ & \\
\hline \multicolumn{4}{|l|}{ Grade of surgery } \\
\hline Minor & Reference & & $24.2(4.2-53.9)$ \\
\hline Intermediate & $1.74(0.94-3.24)$ & 0.08 & \\
\hline Major & $3.21(1.70-6.07)$ & $<0.001$ & \\
\hline \multicolumn{4}{|l|}{ Urgency of surgery } \\
\hline Elective & Reference & & $25.5(5.1-55.8)$ \\
\hline Urgent & $2.10(1.17-3.75)$ & 0.01 & \\
\hline Emergency & $2.53(1.39-4.58)$ & 0.002 & \\
\hline \multicolumn{4}{|l|}{ Surgical specialty } \\
\hline Orthopaedic & $0.20(0.10-0.42)$ & $<0.001$ & \\
\hline Gynaecology & $0.24(0.06-1.03)$ & 0.54 & \\
\hline Upper GIT & $2.14(1.15-3.99)$ & 0.02 & $3.6(0.3-9.7)$ \\
\hline \multicolumn{4}{|c|}{ Primary indication for surgery } \\
\hline Non-communicable & Reference & & \\
\hline Infective & $1.89(1.06-3.38)$ & 0.03 & NS \\
\hline Injury & $3.35(1.87-6.02)$ & $<0.001$ & NS \\
\hline \multicolumn{4}{|l|}{ Comorbid disorder } \\
\hline Metastatic cancer & $2.96(1.39-6.29)$ & 0.01 & $2.2(0.2-5.8)$ \\
\hline Stroke or TIA & $2.82(1.09-7.32)$ & 0.03 & $1.8(0.1-4.7)$ \\
\hline
\end{tabular}

mortality (25.5\%; 95\% CI $5.1-55.8)$ and critical care admission (23.7\%; 95\% CI 4.7 51.4). Unplanned critical care admission had a significantly higher associated mortality than planned admission. The SASOS data suggest that NCDs (reflected by metastatic cancers and stroke) have a larger proportional contribution to mortality than communicable diseases and injuries.

When compared with the EuSOS data, SASOS patients were significantly younger and there were fewer non-communicable risk factors. The most common comorbidity was HIV infection, although it was not associated with in-hospital mortality. SASOS patients underwent significantly more urgent and emergency surgery $(p<0.0001)$. Although SASOS patients had a significantly lower rate of critical care admissions than those in EuSOS (6.5\%; 95\% CI 5.7 - 7.3 v. $7.7 \%$; 95\% CI 7.5 - 8.0), they had significantly more unplanned critical care admissions $(p<0.0001)$. SASOS patients spent longer in critical care than EuSOS patients (3 days; IQR 1 - 7 v. 1.2 days; IQR 0.9 - 3.6, respectively).

\section{Strengths and weaknesses of SASOS}

The strengths of this study are that it included all the government-funded, public sector, tertiary hospitals in SA, 41/74 (55.4\%) of the government-funded regional hospitals, and $50 / 410(12.2 \%)$ of all government-funded hospitals. ${ }^{[14]}$ SASOS is therefore possibly generalisable to government-funded regional and tertiary hospitals in SA.

By adopting the EuSOS protocol with minor modifications, SASOS provides data that are directly comparable with the EuSOS data and 28 European countries. This has important implications for generating consistent outcomes data for the Commission for Global Surgery. These are the first data from SA. 


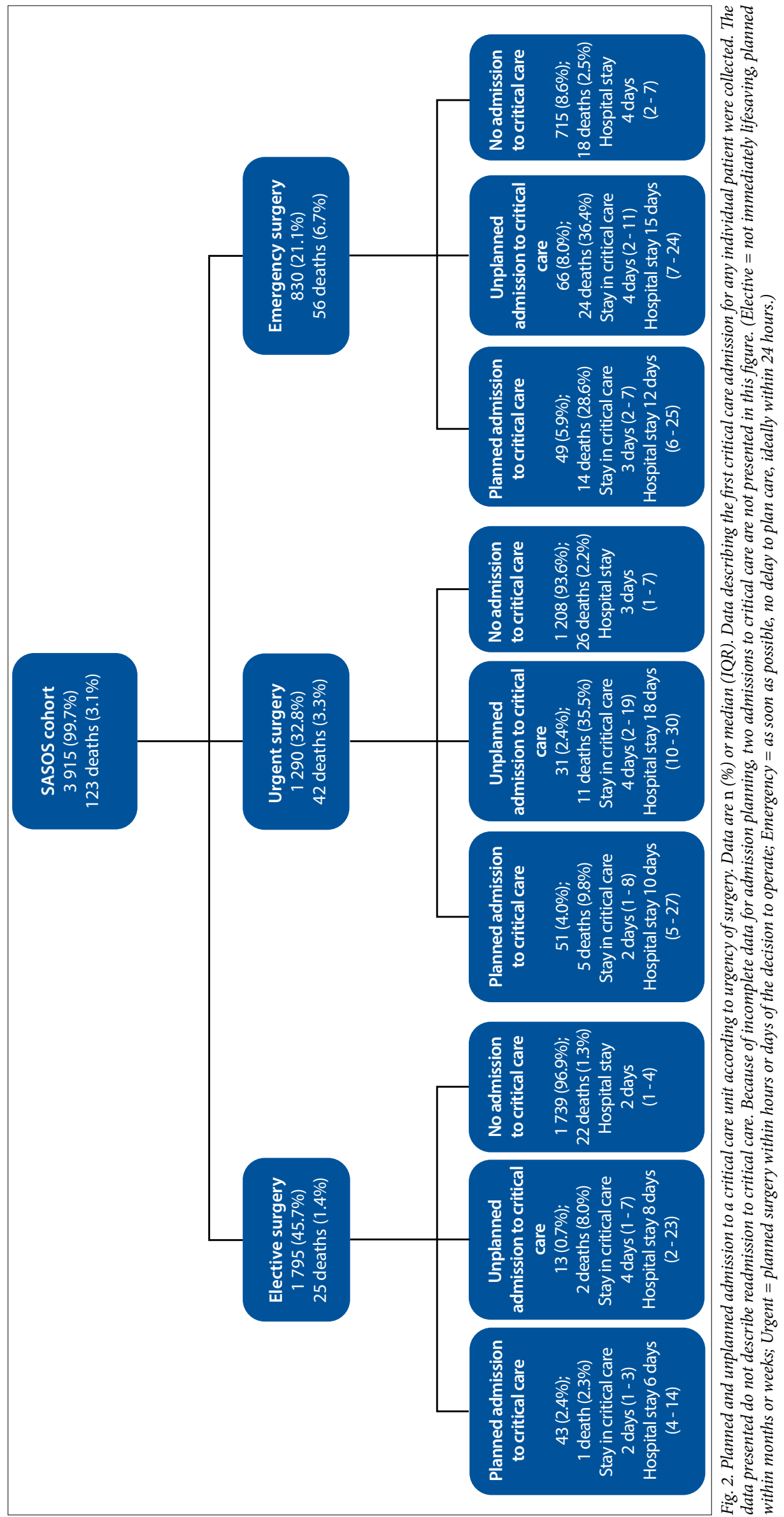

Furthermore, this is the first study that has addressed the proportional contribution of the burden of disease categories (communicable diseases, NCDs and injuries) to perioperative mortality. The independent risk factors for in-hospital mortality were similar to those in EuSOS, suggesting that these risk factors are globally consistent. These risk factors are dominated by NCDs. As a result, the NCD burden contributes most to perioperative mortality. The SASOS data also provide external validation of the importance of non-communicable risk factors for perioperative mortality.

Potential weaknesses of the study are that it only included $8 / 259$ (3.1\%) of the district hospitals in SA. ${ }^{[14]}$ It is inappropriate to extrapolate the SASOS data to district hospitals, as although surgery may be limited in district hospitals, it is possible that the mortality is higher owing to limited resources, unmet surgical needs and a lack of provision for predominantly emergency surgery ${ }^{[15]}$ SASOS also only provides data from government-funded public sector hospitals in SA. It is possible that the burden of disease, case mix, prior health status, surgical techniques and outcomes may differ in the private sector hospitals.

\section{Interpretation of the study}

Based on the estimates of surgical volumes in SA by Weiser et al., ${ }^{[1]}$ the SA population statistics for $2013^{[16]}$ and the SASOS data, the estimated mortality of surgery in adults $(\geq 20$ years of age) in SA is between 76 and 128 deaths per 100000 , which is equivalent to $7.2 \%$ and $12.1 \%$ of all deaths in the country. It is inappropriate to directly compare the mortality rate between SASOS and EuSOS, as SASOS was censored at 30 days, and the SASOS patients had significantly fewer comorbidities that are established as risk factors for perioperative mortality. As the crude mortality rates for SASOS and EuSOS are similar, it is possible that a risk-adjusted mortality rate for surgery may be higher in SA.

SASOS suggests that the benefits associated with surgery ${ }^{[4]}$ are compromised for a number of reasons. The contributing SA hospitals had on average fewer operating rooms and critical care beds than reported in EuSOS, even though the majority of the hospitals in SASOS were regional and tertiary hospitals. This may have contributed to the finding that over $50 \%$ of patients who died were not admitted to a critical care unit. The potential benefits of surgery were further compromised by predominantly urgent and emergency surgery, resulting in more unplanned critical care admissions, 
Table 3. Critical care admission

\begin{tabular}{|c|c|c|c|c|c|c|c|}
\hline & $\begin{array}{l}\text { No critical } \\
\text { care } \\
\text { admission } \\
(N=3672)\end{array}$ & $\begin{array}{l}\text { Any critical } \\
\text { care } \\
\text { admission } \\
(N=255)\end{array}$ & $\mathrm{OR}^{\dagger}(95 \% \mathrm{CI})$ & $p$-value & $\begin{array}{l}\text { Planned } \\
\text { critical care } \\
\text { admission } \\
(N=144)\end{array}$ & $\begin{array}{l}\text { Unplanned } \\
\text { critical care } \\
\text { admission } \\
(N=111)\end{array}$ & $p$-value \\
\hline Age (years), mean (SD) & $43.5(17.7)$ & $43.7(16.7)$ & $1.00(0.99-1.01)$ & 0.89 & $45.7(17.0)$ & $41.1(15.9)$ & 0.03 \\
\hline Male, $n(\%)^{*}$ & $1835(50.0)$ & $159(62.4)$ & $1.66(1.27-2.15)$ & $<0.001$ & $84(58.3)$ & $75(67.6)$ & 0.15 \\
\hline Smoker, $n(\%)$ & $1015(28.2)$ & $67(28.5)$ & $1.02(0.76-1.36)$ & 0.92 & $41(30.4)$ & $26(26.0)$ & 0.56 \\
\hline \multicolumn{8}{|l|}{ ASA category, $n(\%)$} \\
\hline 1 & $1696(46.6)$ & $46(18.1)$ & Reference & & $21(14.6)$ & $25(22.7)$ & 0.07 \\
\hline 2 & $1300(35.7)$ & $47(18.5)$ & $1.34(0.88-2.01)$ & 0.17 & $31(21.5)$ & $16(14.5)$ & \\
\hline 3 & $561(15.4)$ & $102(40.2)$ & $6.70(4.67-9.62)$ & $<0.001$ & $62(43.1)$ & $40(36.4)$ & \\
\hline 4 & $78(2.1)$ & $53(20.9)$ & $25.05(15.89-39.51)$ & $<0.001$ & $29(20.1)$ & $24(21.8)$ & \\
\hline 5 & $8(0.2)$ & $6(2.4)$ & $27.65(9.22-82.93)$ & $<0.001$ & $1(0.7)$ & $5(4.5)$ & \\
\hline \multicolumn{8}{|l|}{ Grade of surgery, $n(\%)$} \\
\hline Minor & $1382(38.0)$ & $21(8.4)$ & Reference & & $10(7.1)$ & $11(10.1)$ & 0.13 \\
\hline Intermediate & $1596(43.9)$ & $76(30.4)$ & $3.13(1.92-5.11)$ & $<0.001$ & $37(26.2)$ & $39(35.8)$ & \\
\hline Major & $659(18.1)$ & $153(61.2)$ & $15.33(9.62-24.41)$ & $<0.001$ & $94(66.7)$ & $59(54.1)$ & \\
\hline \multicolumn{8}{|l|}{ Urgency of surgery, $n(\%)$} \\
\hline Elective & $1738(47.5)$ & $56(22.1)$ & Reference & & $43(30.1)$ & $13(11.8)$ & $<0.001$ \\
\hline Urgent & $1208(33.0)$ & $82(32.4)$ & $2.11(1.49-2.98)$ & $<0.001$ & $51(35.7)$ & $31(28.2)$ & \\
\hline Emergency & $715(19.5)$ & $115(45.5)$ & $4.99(3.59-6.95)$ & $<0.001$ & $49(34.3)$ & $66(60.0)$ & \\
\hline Laparoscopic surgery, $n(\%)$ & $150(4.1)$ & $8(3.2)$ & $0.78(0.38-1.61)$ & 0.50 & $5(3.5)$ & $3(2.8)$ & 0.74 \\
\hline \multicolumn{8}{|l|}{ Surgical specialty, $n(\%)$} \\
\hline Orthopaedic & $1089(29.7)$ & $23(9.1)$ & $0.47(0.26-0.85)$ & 0.01 & $10(7.0)$ & $13(11.7)$ & 0.20 \\
\hline Breast & $109(3.0)$ & $0(0.0)$ & & 1.00 & $0(0.0)$ & $0(0.0)$ & \\
\hline Gynaecology & $515(14.0)$ & $10(4.0)$ & $0.43(0.20-0.92)$ & 0.03 & $3(2.1)$ & $7(6.3)$ & 0.09 \\
\hline Vascular & $113(3.1)$ & $21(8.3)$ & $4.14(2.2-7.79)$ & $<0.001$ & $10(7.0)$ & $11(9.9)$ & 0.49 \\
\hline Upper GIT & $122(3.3)$ & $32(12.6)$ & $5.84(3.28-10.41)$ & $<0.001$ & $15(10.6)$ & $17(15.3)$ & 0.26 \\
\hline Lower GIT & $364(9.9)$ & $36(14.2)$ & $2.20(1.27-3.81)$ & 0.01 & $18(12.7)$ & $18(16.2)$ & 0.47 \\
\hline Hepatobiliary & $80(2.2)$ & $8(3.2)$ & $2.23(0.96-5.18)$ & 0.06 & $5(3.5)$ & $3(2.7)$ & 0.73 \\
\hline Plastics & $233(6.4)$ & $9(3.6)$ & $0.86(0.39-1.90)$ & 0.71 & $6(4.2)$ & $3(2.7)$ & 0.53 \\
\hline Urology & $202(5.5)$ & $10(4.0)$ & $1.10(0.51-2.37)$ & 0.80 & $8(5.6)$ & $2(1.8)$ & 0.13 \\
\hline Kidney & $12(0.3)$ & $1(0.4)$ & $1.86(0.23-14.92)$ & 0.56 & $1(0.7)$ & $0(0.0)$ & 0.38 \\
\hline Head and neck & $203(5.5)$ & $19(7.5)$ & $2.09(1.10-3.94)$ & 0.02 & $13(9.2)$ & $6(5.4)$ & 0.34 \\
\hline Neurosurgery & $88(2.4)$ & $45(17.8)$ & $11.39(6.52-19.90)$ & $<0.001$ & $32(22.5)$ & $13(11.7)$ & 0.03 \\
\hline Thoracic & $48(1.3)$ & $17(6.7)$ & $7.89(3.92-15.87)$ & $<0.001$ & $14(9.9)$ & $3(2.7)$ & 0.04 \\
\hline Other & $490(13.4)$ & $22(8.7)$ & Reference & & $7(4.9)$ & $15(13.5)$ & 0.02 \\
\hline \multicolumn{8}{|l|}{ Primary indication for surgery, $n(\%)$} \\
\hline Non-communicable & $1775(48.5)$ & $105(41.5)$ & Reference & & $74(52.1)$ & $31(27.9)$ & $<0.001$ \\
\hline Injury & $1194(32.6)$ & $103(40.7)$ & $1.44(1.09-1.92)$ & 0.01 & $46(32.4)$ & $57(51.4)$ & \\
\hline Infective & $691(18.9)$ & $45(17.8)$ & $1.11(0.78-1.60)$ & 0.56 & $22(15.5)$ & $23(20.7)$ & \\
\hline \multicolumn{8}{|l|}{ Comorbid disorder } \\
\hline Coronary artery disease & $145(4.0)$ & $15(6.1)$ & $1.56(0.90-2.71)$ & 0.11 & $12(8.7)$ & $3(2.8)$ & 0.06 \\
\hline Congestive heart failure & $47(1.3)$ & $8(3.3)$ & $2.57(1.20-5.50)$ & 0.02 & $5(3.6)$ & $3(2.8)$ & 0.72 \\
\hline Diabetes mellitus (no insulin) & $209(5.8)$ & $16(6.5)$ & $1.14(0.68-1.93)$ & 0.62 & $8(5.8)$ & $8(7.5)$ & 0.61 \\
\hline Diabetes mellitus with insulin therapy & $163(4.5)$ & $8(3.3)$ & $0.72(0.35-1.48)$ & 0.37 & $1(0.7)$ & $7(6.5)$ & 0.01 \\
\hline
\end{tabular}


Table 3. (continued) Critical care admission

\begin{tabular}{|c|c|c|c|c|c|c|c|}
\hline & $\begin{array}{l}\text { No critical } \\
\text { care } \\
\text { admission } \\
(N=3672)\end{array}$ & $\begin{array}{l}\text { Any critical } \\
\text { care } \\
\text { admission } \\
(N=255)\end{array}$ & $\mathrm{OR}^{\dagger}(95 \% \mathrm{CI})$ & $p$-value & $\begin{array}{l}\text { Planned } \\
\text { critical care } \\
\text { admission } \\
(N=144)\end{array}$ & $\begin{array}{l}\text { Unplanned } \\
\text { critical care } \\
\text { admission } \\
(N=111)\end{array}$ & $p$-value \\
\hline Metastatic cancer & $90(2.5)$ & $11(4.5)$ & $1.85(0.97-3.50)$ & 0.06 & $8(5.8)$ & $3(2.8)$ & 0.26 \\
\hline Cirrhosis & $6(0.2)$ & $1(0.4)$ & $2.47(0.30-20.60)$ & 0.40 & $1(0.7)$ & $0(0.0)$ & 0.38 \\
\hline Stroke or TIA & $50(1.4)$ & $5(2.0)$ & $1.49(0.59-3.77)$ & 0.40 & $1(0.7)$ & $4(3.7)$ & 0.10 \\
\hline COPD/asthma & $212(5.9)$ & $28(11.4)$ & $2.08(1.37-3.15)$ & 0.001 & $19(13.8)$ & $9(8.4)$ & 0.23 \\
\hline HIV-positive/AIDS & $489(13.5)$ & $20(8.2)$ & $0.57(0.36-0.91)$ & 0.02 & $11(8.0)$ & $9(8.4)$ & 1.00 \\
\hline
\end{tabular}

Table 4. Three-level generalised linear model for critical care admission

\begin{tabular}{|c|c|c|c|}
\hline & $\mathrm{OR}^{\star}(95 \% \mathrm{CI})$ & $p$-value & $\begin{array}{l}\text { PAR } \\
\%(95 \% \mathrm{CI})\end{array}$ \\
\hline Male & $1.15(0.81-1.65)$ & 0.44 & \\
\hline \multicolumn{4}{|l|}{ ASA category } \\
\hline 1 & Reference & & $26.1(5.4-55.7)$ \\
\hline 2 & $1.78(1.10-2.88)$ & 0.02 & \\
\hline 3 & $5.87(3.73-9.24)$ & $<0.001$ & \\
\hline 4 & $13.82(7.74-24.70)$ & $<0.001$ & \\
\hline 5 & $7.18(1.88-27.38)$ & $<0.001$ & \\
\hline \multicolumn{4}{|l|}{ Grade of surgery } \\
\hline Minor & Reference & & $35.3(9.5-70.8)$ \\
\hline Intermediate & $2.55(1.47-4.42)$ & 0.001 & \\
\hline Major & $10.93(6.29-18.97)$ & $<0.001$ & \\
\hline \multicolumn{4}{|l|}{ Urgency of surgery } \\
\hline Elective & Reference & & $23.7(4.7-51.4)$ \\
\hline Urgent & $2.57(1.65-3.99)$ & $<0.001$ & \\
\hline Emergency & $3.19(2.07-4.93)$ & $<0.001$ & \\
\hline \multicolumn{4}{|l|}{ Surgical specialty } \\
\hline Orthopaedic & $0.25(0.12-0.53)$ & $<0.001$ & \\
\hline Breast & & 1.00 & \\
\hline Gynaecology & $0.63(0.26-1.54)$ & 0.31 & \\
\hline Vascular & $0.91(0.42-1.96)$ & 0.80 & \\
\hline Upper GIT & $2.36(1.18-4.73)$ & 0.02 & $3.5(0.4-8.6)$ \\
\hline Lower GIT & $1.17(0.60-2.27)$ & 0.65 & \\
\hline Hepatobiliary & $2.39(0.87-6.59)$ & 0.09 & \\
\hline Plastics & $1.10(0.45-2.66)$ & 0.84 & \\
\hline Urology & $1.28(0.53-3.07)$ & 0.58 & \\
\hline Kidney & $0.67(0.07-6.36)$ & 0.73 & \\
\hline Head and neck & $2.40(1.13-5.12)$ & 0.02 & $2.3(0.4-5.1)$ \\
\hline Neurosurgery & $3.49(1.75-6.98)$ & $<0.001$ & $5.9(0.7-13.9)$ \\
\hline Thoracic & $2.90(1.20-7.05)$ & 0.02 & NS \\
\hline Other & Reference & & \\
\hline
\end{tabular}

an associated increased mortality, longer critical care stay, and therefore less critical care resources for patients. Urgency of surgery has a far larger proportional contribution to perioperative mortality than other preoperative surgical risk factors.

Importantly, the mortality and critical care admission rate associated with urgent and emergency surgery are mainly due to factors other than injuries and violence, as injuries have little or no contribution to the attributable risk in SASOS. The importance of the PAR is that it quantifies the proportion of cases that can be attributed to a risk factor, ${ }^{[13]}$ which permits stratification of preventive public health interventions on the outcome. The majority of urgent and emergency surgery occurs across all surgical disciplines and comorbidities, and late presentation of patients for surgery in SA contributes significantly to surgical morbidity and mortality. This is important in strategic planning to provide safe surgery in SA.

The SASOS data suggest that NCDs have a larger proportional contribution to morbidity and mortality than infections and injuries. The contribution of NCDs to perioperative mortality in SA may be expected to increase as a result of epidemiological transition ${ }^{[17]}$ and the success of HIV therapy in increasing life expectancy. ${ }^{[18]}$

The SASOS data suggest that the SA health budget needs to allocate more funding: (i) to primary healthcare to identify and manage potential surgical pathologies; and (ii) to hospital and tertiary healthcare services to provide sufficient surgical and critical care services to decrease surgical morbidity and mortality.

The need for urgent and emergency surgery may have arisen from a number of factors, including: (i) poor primary healthcare and late detection of surgical pathology; (ii) poor medical management of 
Table 4. (continued) Three-level generalised linear model for critical care admission

\begin{tabular}{|c|c|c|c|}
\hline & $\mathrm{OR}^{\star}(95 \% \mathrm{CI})$ & $p$-value & $\begin{array}{l}\text { PAR } \\
\%(95 \% \text { CI })\end{array}$ \\
\hline \multicolumn{4}{|c|}{ Primary indication for surgery } \\
\hline Other & Reference & & \\
\hline Injury & $2.18(1.46-3.27)$ & $<0.001$ & NS \\
\hline \multicolumn{4}{|l|}{ Comorbid disorder } \\
\hline Congestive heart failure & $1.16(0.45-2.96)$ & 0.76 & \\
\hline COPD/asthma & $0.96(0.56-1.64)$ & 0.87 & \\
\hline HIV-positive/AIDS & $0.56(0.32-0.98)$ & 0.043 & \\
\hline
\end{tabular}

\section{Table 5. Comparison between SASOS and EuSOS data}

\begin{tabular}{|c|c|c|c|}
\hline & SASOS $(N=3$ 927) & EuSOS $(N=44657)$ & $p$-value \\
\hline \multicolumn{4}{|l|}{ Risk predictors } \\
\hline Age, mean (SD) & $43.5(17.6)$ & $56.7(18.5)$ & $<0.0001$ \\
\hline ASA $1, n(\%)$ & $1743(44.7)$ & $11642(26.1)$ & $<0.0001$ \\
\hline Elective surgery, $n(\%)$ & $1795(45.8)$ & $35049(78.5)$ & $<0.0001$ \\
\hline Minor surgery, $n(\%)$ & $1403(36.1)$ & $12041(27.0)$ & $<0.0001$ \\
\hline \multicolumn{4}{|l|}{ Most common surgeries by rank, $n(\%)$} \\
\hline 1 & $\begin{array}{l}\text { Orthopaedic } \\
1112(28.4)^{*}\end{array}$ & $\begin{array}{l}\text { Orthopaedic } \\
12214(27.4)\end{array}$ & \\
\hline 2 & $\begin{array}{l}\text { Gynaecology } \\
525(13.4)^{\dagger}\end{array}$ & $\begin{array}{l}\text { Head and neck } \\
5640(12.6)\end{array}$ & \\
\hline 3 & $\begin{array}{l}\text { Lower } \\
\text { gastrointestinal } \\
400(10.2)^{\star}\end{array}$ & $\begin{array}{l}\text { Lower } \\
\text { gastrointestinal } \\
4972(11.1)\end{array}$ & \\
\hline 4 & Plastics $242(6.2)^{*}$ & Urology 4881 (10.9) & \\
\hline 5 & $\begin{array}{l}\text { Head and neck } \\
222(5.7)^{\dagger}\end{array}$ & $\begin{array}{l}\text { Gynaecology } \\
3972(8.9)\end{array}$ & \\
\hline \multicolumn{4}{|c|}{ Most common comorbidities by rank, $n(\%)$} \\
\hline 1 & $\begin{array}{l}\text { HIV-positive/ } \\
\text { AIDS } 509(13.2)^{\ddagger}\end{array}$ & $\begin{array}{l}\text { Coronary artery } \\
\text { disease } 6274(14.0)\end{array}$ & \\
\hline 2 & $\begin{array}{l}\text { Diabetes } \\
396(10.1)^{\dagger}\end{array}$ & $\begin{array}{l}\text { Diabetes } \\
5576(12.5)\end{array}$ & \\
\hline 3 & $\begin{array}{l}\text { COPD/asthma } \\
240(6.2)^{\dagger}\end{array}$ & $\begin{array}{l}\text { COPD/asthma } \\
5162(11.6)\end{array}$ & \\
\hline 4 & $\begin{array}{l}\text { Coronary artery } \\
\text { disease } 160(4.1)^{\dagger}\end{array}$ & $\begin{array}{l}\text { Metastatic cancer } \\
2173(4.9)\end{array}$ & \\
\hline 5 & $\begin{array}{l}\text { Metastatic cancer } \\
101(2.6)^{\dagger}\end{array}$ & $\begin{array}{l}\text { Congestive heart } \\
\text { failure } 2154(4.8)\end{array}$ & \\
\hline \multicolumn{4}{|l|}{ Outcomes, $n(\%)$} \\
\hline Critical care admission & $255(6.5)$ & $3599(7.7)$ & 0.01 \\
\hline Unplanned critical care admission & $111 / 255(43.5)$ & $1044 / 3851(27.1)$ & $<0.0001$ \\
\hline $\begin{array}{l}\text { Mortality without critical care } \\
\text { admission }\end{array}$ & $67 / 123(53.7)$ & $1425 / 1987(71.7)$ & $<0.0001$ \\
\hline $\begin{array}{l}\text { Mortality with critical care } \\
\text { admission }\end{array}$ & $57 / 255(22.4)$ & $506 / 3599(14.1)$ & 0.0006 \\
\hline $\begin{array}{l}{ }^{*} \text { Not significantly different from EuSOS prevalence } \\
{ }^{p} p<0.0001 \text { compared with EuSOS prevalence. } \\
{ }^{\prime} \text { HIV status not reported in EuSOS. }\end{array}$ & & & \\
\hline
\end{tabular}

other comorbidities, with a negative impact on surgical outcomes; (iii) an inefficient surgical referral system; and (iv) insufficient surgical and critical care services, resulting in surgical operative delay. The data collected do not permit determination of the proportional contribution of these factors to urgent and emergency surgery, however, although the data did identify fewer surgical and critical care resources compared with Europe. It is also possible that the high proportion of urgent and emergency surgery may further contribute to increased mortality in SA patients. With a view to improving surgical outcomes, investigation of the contribution of the factors determining need for urgent/emergency surgery should be considered a public health priority.

\section{Conclusion}

In order to realise the full benefits of surgery in SA, it is important that a proactive strategy be adopted to increase surgical and critical care resources. Strategies aimed at decreasing the burden of urgent and emergent surgery should be implemented.

Funding disclosure. The study was funded by the South African Society of Anaesthesiologists and the Vascular Association of South Africa. The study website was maintained by the Anaesthesia Network for South Africa. They had no role in the study design, data acquisition, data analysis or writing up of the paper.

Conflicts of interest and source of funding. T M Esterhuizen and R M R Moreno received payment for statistical analyses for SASOS from SASOS grant funds for the submitted work, and R M Pearse (RMP) received grants and personal fees from Nestlé Health Sciences, personal fees from Massimo Inc., personal fees from Edwards Lifesciences and grants and non-financial support from LiDCO Ltd that might have an interest in the submitted work in the previous 3 years. RMP was first author of EuSOS and A Hoeft, R Moreno and A Rhodes were authors of EuSOS. The remainder of the authors have nothing to disclose.

\section{References}

1. Weiser TG, Regenbogen SE, Thompson KD, et al. An estimation of the global volume of surgery: A modelling strategy based on available data. Lancet 2008;372(9633):139-144. [http://dx.doi. org/10.1016/S0140-6736(08)60878-8]

2. Devereaux PJ, Chan MT, Alonso-Coello P, et al. Association between Devereaux PJ,Chan MT, Alonso-Coello P, et al. Association between
postoperative troponin levels and 30-day mortality among patients postoperative troponin levels and 30-day mortality among patients
undergoing noncardiac surgery. JAMA 2012;307(21):2295-2304. undergoing noncardiac surgery. JAMA

[http://dx.doi.org/10.1001/jama.2012.5502]

3. Pearse RM, Moreno RP, Bauer P, et al. Mortality after surgery in Europe: A 7 day cohort study. Lancet 2012;380(9847):10591065. [http://dx.doi.org/10.1016/S0140-6736(12)61148-9]

4. Grimes CE, Henry JA, Maraka J, Mkandawire NC, Cotton M. Cost-effectiveness of surgery in low- and middle-income countries: A systematic review. World J Surg 2014;38(1):252263. [http://dx.doi.org/10.1007/s00268-013-2243-y] 
5. Meara JG, Hagander L, Leather AJ. Surgery and global health: A Lancet Commission. Lancet 2014;383(9911):12-13. [http://dx.doi.org/10.1016/S0140-6736(13)62345-4]

6. Coovadia H, Jewkes R, Barron P, Sanders D, McIntyre D. The health and health system of South Africa: Historical roots of current public health challenges. Lancet 2009;374(9692):817-834. [http://dx.doi. org/10.1016/S0140-6736(09)60951-X]

7. Bicerd BM. An eshesin for vasul- procedures: How do South African patients difer? Southen frican Journal of Angesher 13.2008.10872536

8. Lozano R, Naghavi M, Foreman K, et al. Global and regional mortality from 235 causes of death for 20 age groups in 1990 and 2010: A systematic analysis for the Global Burden of Disease Study 2010. Lancet 2012;380(9859):2095-2128. [http://dx.doi.org/10.1016/S0140-6736(12)61728-0]

9. Cacala SR, Mafana E, Thomson SR, Smith A. Prevalence of HIV status and CD4 counts in a surgical cohort: Their relationship to clinical outcome. Ann R Coll Surg Engl 2006;88(1):46-51. [http://dx.doi. org/10.1308/003588406X83050

10. Von Elm E, Altman DG, Egger M, Pocock SJ, Gotzsche PC, Vandenbroucke JP. The Strengthening the Reporting of Observational Studies in Epidemiology (STROBE) statement: Guidelines for reportin observational studies. PLoS Med 2007;4(10):e296. [http://dx.doi.org/10.1371/journal.pmed.0040296]

11. Peduzzi P, Concato J, Kemper E, Holford TR, Feinstein AR. A simulation study of the number of events per variable in logistic regression analysis. J Clin Epidemiol 1996;49(12):1373-1379. [http:// events per variable in logistic regression and
dx.doi.org/10.1016/S0895-4356(96)00236-3]

12. Steyerberg EW. Clinical Prediction Models. New York: Springer, 2010.

13. Ruckinger $S$. fractions in large scale surveys considering multiple risk factors. BMC Med Res Methodol 2009:9:7. fractions in large scale surveys considering [http://dx.doi.org/10.1186/1471-2288-9-7]

14. Health Systems Trust. Health Indicators Advanced Search. http://www.hst.org.za/health-indicatorsadvanced-search (accessed 2 February 2015)

15. Grimes CE, Law RS, Borgstein ES, Mkandawire NC, Lavy CB. Systematic review of met and unmet need of surgical disease in rural sub-Saharan Africa. World J Surg 2012;36(1):8-23. [http://dx.doi. org/10.1007/s00268-011-1330-1]

16. Statistical release P0302. Mid-year population estimates. 2013. http://www.statssa.gov.za/publication p0302/p03022013.pdf (accessed 14 October 2014)

17. Opie LH, Mayosi BM. Cardiovascular disease in sub-Saharan Africa. Circulation 2005;112(23):35363540. [http://dx.doi.org/10.1161/CIRCULATIONAHA.105.597765]

18. Mayosi BM, Benatar SR. Health and health care in South Africa - 20 years after Mandela. N Engl J Med 2014;371(14):1344-1353. [http://dx.doi.org/10.1056/NEJMsr1405012]

Accepted 9 March 2015.

\section{Appendix 1. Full author list}

B M Biccard, PhD, Perioperative Research Group, Discipline of Anaesthesiology and Critical Care, School of Clinical Medicine, College of Health Sciences, Nelson R Mandela School of Medicine, University of KwaZulu-Natal, Durban, South Africa; T E Madiba, $\mathrm{PhD}$, Professor and Head, Department of Surgery, School of Clinical Medicine, College of Health Sciences, Nelson R Mandela School of Medicine, University of KwaZulu-Natal, Durban, South Africa; R M Pearse, MD (Res), Professor of Intensive Care Medicine, Queen Mary University of London, Royal London Hospital, London, UK; P Alexandris, FCA (SA), Head of Department, Department of Anaesthetics, Livingstone Hospital, Port Elizabeth, South Africa; D R Bhagwandass, MMed (Anaesthesiology), Head of Department, Department of Anaesthesiology, School of Medicine, Faculty of Health Sciences, University of Limpopo (Medunsa campus), Pretoria, South Africa; K D Boffard, FRCS, Professor and Head, Department of Surgery, Faculty of Health Sciences, University of the Witwatersrand and Charlotte Maxeke Johannesburg Academic Hospital, Johannesburg, South Africa; G A Buga, PhD, Head of Department, Department of Obstetrics and Gynaecology, Faculty of Health Sciences, Walter Sisulu University and Nelson Mandela Academic Hospital, Mthatha, Eastern Cape, South Africa; E Cloete, FCA (SA), Department of Anaesthesia, Groote Schuur Hospital and Faculty of Health Sciences, University of Cape Town, South Africa; A Coetzee, DSc, Head of Department, Department of Anaesthesiology and Critical Care, Faculty of Medicine and Health Sciences, Stellenbosch University, Tygerberg, Cape Town, South Africa; L Cronje, FCA (SA), Discipline of Anaesthesiology and Critical Care, School of Clinical Medicine, College of Health Sciences, Nelson R Mandela School of Medicine, University of KwaZulu-Natal, Durban, South Africa; A Dhaffala, FCS, Head of Department, Department of Surgery, Faculty of Health Sciences, Walter Sisulu University, Mthatha, Eastern Cape, South Africa; B J Diedericks, MMed (Anes), Head of Department, Department of Anaesthesiology, Faculty of
Health Sciences, University of the Free State, Bloemfontein, South Africa; R S du Toit, MMed (Surg), Head of Department, Department of Surgery, Faculty of Health Sciences, University of the Free State, Bloemfontein, South Africa; T M Esterhuizen, MSc (Epidemiology), Biostatistician, Stellenbosch University, Tygerberg, Cape Town, South Africa; C Fourie, MMed (Anaes), Head of Department, Tygerberg Surgical ICU, Stellenbosch University, Tygerberg, Cape Town, South Africa; A Goolam Mahomed, FCP (SA), Head of Critical Care, School of Medicine, Faculty of Health Sciences, University of Limpopo (Medunsa campus), Pretoria, South Africa; P D Gopalan, FCA (SA), Head of Department, Discipline of Anaesthesiology and Critical Care, School of Clinical Medicine, College of Health Sciences, Nelson R Mandela School of Medicine, University of KwaZulu-Natal, Durban, South Africa; F Guidozzi, FCOG, Head of Department, Department of Obstetrics and Gynaecology, Faculty of Health Sciences, University of the Witwatersrand and Charlotte Maxeke Johannesburg Academic Hospital, Johannesburg, South Africa; R W Hewson, FFICM, Barts Health NHS Trust, Adult Critical Care Unit, Royal London Hospital, Whitechapel Road, London, UK; A Hoeft, PhD, Professor and Chairman, Department of Anesthesiology and Intensive Care Medicine, University Hospital of Bonn, Germany; I Joubert, FCA (SA), Head of Department, Department of Critical Care, Faculty of Health Sciences, University of Cape Town, South Africa; D Kahn, ChM, Head of Department, Department of Surgery, Faculty of Health Sciences, University of Cape Town, South Africa; M Klipin, FCS (SA), Senior Specialist, Department of Surgery, Faculty of Health Sciences, University of the Witwatersrand, Johannesburg, South Africa; H-L Kluyts, MMed (Anaes), Department of Anaesthesiology, School of Medicine, Faculty of Health Sciences, University of Pretoria, South Africa; M Z Koto, FCS (SA), Head of Department, Department of Surgery, School of Medicine, Faculty of Health Sciences, University of Limpopo (Medunsa campus), Pretoria, South Africa; B G Lindeque, MMed (O\&G), Head of Department, Department of Obstetrics and Gynaecology, School of Medicine, Faculty of Health Sciences, University of Pretoria, South Africa; A C Lundgren, PhD, Head of Department, Department of Anaesthesiology, Faculty of Health Sciences, University of the Witwatersrand, Johannesburg, South Africa; R Machekano, PhD, Head of Department, Biostatistics Unit, Department of Interdisciplinary Health Sciences, Faculty of Medicine and Health Sciences, Stellenbosch University, Tygerberg, Cape Town, South Africa; L R Mathivha, DBS (BM), Intensive Care Unit, Chris Hani Baragwanath Academic Hospital and Faculty of Health Sciences, University of the Witwatersrand, Johannesburg, South Africa; T R Mokoena, DPhil (Oxon), Head of Department, Department of Surgery, School of Medicine, Faculty of Health Sciences, University of Pretoria, South Africa; S Monokoane, FCOG (SA), Head of Department, Department of Obstetrics and Gynaecology, School of Medicine, Faculty of Health Sciences, University of Limpopo (Medunsa campus), Pretoria, South Africa; R M R Moreno, PhD, UCINC, Hospital de São José, Centro Hospitalar de Lisboa Central, Lisbon, Portugal; D F Morrell, FCA (SA), Head of Department, Department of Anaesthesiology, Frere Hospital, East London, Eastern Cape, South Africa; B Mrara, FCA (SA), Head of Department, Department of Anaesthesiology, Faculty of Health Sciences, Walter Sisulu University and Nelson Mandela Academic Hospital, Mthatha, South Africa; M Ntlhe, FCS (SA), Senior Lecturer and Senior Specialist, Department of Surgery, School of Medicine, Faculty of Health Sciences, University of Pretoria and Steve Biko Academic Hospital, South Africa; E E Oosthuizen, MMed (Anaes), Head of Department, Department of Anaesthesiology, Charlotte Maxeke Johanesburg Academic Hospital, Johannesburg, South Africa; 
S S Pillay, LLM RCP\&S (Irel), Head of Department, Department of Surgery, School of Medicine, Faculty of Health Sciences, University of Limpopo (Polokwane campus), Polokwane, South Africa; J P Pretorius, FCS (SA), Head Clinical Unit, Department of Critical Care, School of Medicine, Faculty of Health Sciences, University of Pretoria and Clinical Unit Critical Care, Department of Surgery, Steve Biko Academic Hospital, Pretoria, South Africa; A Rantloane, MMed, Head of Department, Department of Anaesthesiology, School of Medicine, Faculty of Health Sciences, University of Pretoria, South Africa; A Rhodes, MD (Res), Divisional Chair, Children's, Women's, Diagnostics, Therapeutics \& Critical Care, Consultant in Intensive Care Medicine and Anaesthesia, St George's Healthcare NHS Trust, London, UK; G A Richards, PhD, Head of Department, Department of Critical Care, Faculty of Health Sciences, University of the Witwatersrand, Johannesburg, South Africa; R N Rodseth, PhD, Perioperative Research Group, Discipline of Anaesthesiology and Critical Care, School of Clinical Medicine, College of Health Sciences, Nelson R Mandela School of Medicine, University of KwaZulu-Natal, Durban, South Africa, and Grey's Hospital, Pietermaritzburg, South Africa; M Sebitloane, FCOG, Chief Specialist, Department of Obstetrics and Gynaecology, School of Clinical Medicine, College of Health Sciences, Nelson R Mandela School of Medicine, University of KwaZulu-Natal, Durban, South Africa; M Smith, FCS (SA), Head of Department, Department of Surgery, Faculty of Health Sciences, University of the Witwatersrand, Johannesburg, South Africa; S Spijkerman, FCA (SA), Department of Anaesthesiology, School of Medicine, Faculty of Health Sciences, University of Pretoria, South Africa; M G L Spruyt, MMed (Chir), Head of Department, Department of Critical Care, Faculty of Health Sciences, University of the Free State, Bloemfontein, South Africa; J Swanevelder, FRCA (Hon), Head of Department, Department of Anaesthesiology, Groote Schuur Hospital and Faculty of Health Sciences, University of Cape Town, South Africa; H van der Merwe, FCOG (SA), Department of Obstetrics and Gynaecology, Faculty of Medicine and Health Sciences, Stellenbosch University, Tygerberg, Cape Town, South Africa; B L Warren, FRCS (Edin), Professor and Head, Division of Surgery/Executive Head, Department of Surgical Sciences, Faculty of Medicine and Health Sciences, Stellenbosch, University, Tygerberg, Cape Town, South Africa; P H Wessels, MD, Head of Department, Department of Obstetrics and Gynaecology, Faculty of Health Sciences, University of the Free State, Bloemfontein, South Africa.

\section{Appendix 2. Members of the SASOS group}

SASOS Writing Committee. B M Biccard, T E Madiba, R M Pearse, P Alexandris, D R Bhagwandass, K D Boffard, G A Buga, E Cloete, A Coetzee, L Cronje, A Daffala, B J Diedericks, R S du Toit, T M Esterhuizen, C Fourie, A Goolam Mohamed, P D Gopalan, F Guidozzi, R W Hewson, A Hoeft, I Joubert, D Kahn, M Klipin, H-L Kluyts, M Z Koto, B G Lindeque, A C Lundgren, R Machekano, L R Mathivha, T R Mokoena, S Monokoane, R M R Moreno, D F Morrell, B Mrara, M Ntlhe, E E Oosthuizen, S S Pillay, J P Pretorius, A Rantloane, A Rhodes, G A Richards, R N Rodseth, M Sebitloane, M Smith, S Spijkerman, M G L Spruyt, J Swanevelder, $\mathrm{H}$ van der Merwe, B L Warren, P H Wessels, on behalf of the SASOS investigators.

SASOS Steering Committee. B M Biccard, T E Madiba, R M Pearse, P Alexandris, D R Bhagwandass, K D Boffard, G A Buga, A Coetzee, A Daffala, B J Diedericks, R S du Toit, T M Esterhuizen, C Fourie, A Goolam Mohamed, P D Gopalan, F Guidozzi, R W Hewson, A Hoeft, I Joubert, D Kahn, H-L Kluyts, M Z Koto, B G Lindeque, A C Lundgren, R Machekano, L R Mathivha, T R Mokoena,
S Monokoane, R M R Moreno, D F Morrell, B Mrara, M Ntlhe, E E Oosthuizen, J P Pretorius, A Rantloane, A Rhodes, G A Richards, R N Rodseth, M Sebitloane, M Smith, S Spijkerman, M G L Spruyt, J Swanevelder, $\mathrm{H}$ van der Merwe, B L Warren, P H Wessels, on behalf of the SASOS investigators.

\section{Appendix 3. SASOS investigators and SASOS hospital sites}

Eastern Cape Province. Cecilia Makiwane Hospital: K A Bhat*, B Dokolwana; Frere Hospital: M Coltman*, G Westcott; Livingstone Hospital: L Friedman, D Schmidt*, S Venter; Nelson Mandela Academic Hospital: A Dhaffala, B Mrara*, B Thomas, A Usenbo; Port Elizabeth Provincial Hospital: P Alexandris*, T Serdyn.

Free State Province. Dihlabeng Regional Hospital: W J Selfridge, A J Stals ${ }^{\star}$, W van Zyl, J Vermaak; National Hospital, Pelonomi Regional Hospital and Universitas Academic Hospital: W Barret, M Bester, J de Beer, J Geldenhuys, H Gouws, J H Potgieter*, M Strydom, E Turton.

Gauteng Province. Charlotte Maxeke Johannesburg Academic Hospital: M Klipin, I Mare, V Morford ${ }^{*}$, O Smith; Chris Hani Baragwanath Academic Hospital: Y Adam, W Alhazel, K Antwi, A Atiya, M Ayuk, J Baladakis, S Baloyi, S Barka, N Biyase, N Braam, A Buitenweg, H Burcan, A Cohen, S Cuthbert, Z Dadabhay, S Davies, I du Preez, S Dulabh, W Edridge, S French, M Gayaparsad, J HamuySosa, N Hendricks, T Hlongwane, R Husein, N Hutton, T Jackson, E Jacobs, J Jocum, H Khan, N Khan, A Kiss, V Kumalo, F Lambat, A Lekha, T Leonard, D Leshaba, D Liakos, M Lindy, A C Lundgren, L T Lushiku, K Madiba, N Madima, S Maswime, R Mathiva, J J Mahlangu, M Maisto, P Makwanya, S Maswime, L Matsane, C Mitchell, B Monzon, D Moodley, J Moutlana, G Mukucha, N Murugan, J Nana, N Ndlazi, D Nel${ }^{*}$, G Nethathe, M Nxumalo, Y Nyathela, S Nyimbana, S Omar, J Omoshoro-Jones, A Oosthuizen, E Patel, D Prem, R Pretorius, C Quan, T Ranyaka, K Rathinasamy, C Redelinghuys, N Rikhotso, C Sanders, C Segal, R Setzen, R Sheikh, Z Soni, J Steynberg, M Stubbs, O Tinubu, S Toich, S Tshukutsoane, J Vally, A van der Walt, $\mathrm{N}$ van der Walt, E van Greunen, D van Niekerk, L Variawa, S Veeren, C von Creytz, J Wagner, J Yogeswaram; Dr George Mukhari Hospital: D R Bhagwandass, S L L K Dlamini, A Fourie, A Goolam Mahomed, J Joseph, N Kumar, T C Maganyane, M Z Koto*, S R Motilall; Helen Joseph Hospital: G Cavedon*, K Fisher, H Jahrani, R Maja, J Malumalu, E Semenya, N Zondi; Kalafong Hospital: A Alberts, F Botha, J de Bruin, S Carrim, T Chagwiza, S East, P J H L Fourie, A Joubert, H Kluyts ${ }^{\star}$, J Khosa, T Luvhengo, H Maakamedi, R Maharaj, S Motsitsi, J P Mulder, S Naidoo, H Schutte, A Vlok, M Voigt; Rahima Moosa Mother and Child Hospital: S Chetty ${ }^{*}, M$ de Jager; Steve Biko Academic Hospital: Z Abdool, M Aphane, H J C du Plessis, P R Jujuju, E Moshokoa, M Ngcelwane, L M Ntlhe*, J P Pretorius, S Spijkerman, M Tshifilaro.

KwaZulu-Natal Province. Addington Hospital: M M F Ansermeah, A Dunpath, J Fabian, M Khan, M Maritz, M Naidoo, S Rambarran, P Reddy, U Singh*; Edendale Hospital: N Allorto, D Bishop*, P M Builu, C Cairns, A Dasrath, J de Wet, M den Hoedt, B Grey, M Hayes, B Kusel, N Shangase, R Wise; Grey's Hospital: S Cacala, Z Farina, V Govindasamy ${ }^{*}$, C-H Kruse, C Lee, L Marais, T D Naidoo, C Rajah, R Rodseth, L Ryan, R von Rhaden; King Dinuzulu Hospital: G Alexander, N Brouckaert, B Freeman ${ }^{*}$, S Goga; King Edward VII Hospital: R Chetty, S Chirkut, L Cronje*, K de Vasconcellos, N Z Dube, N S Gama, G Green, R Green Thompson, 
S M Kinoo, P Kistnasami, K Maharaj, M S Moodley, S Mothae, R Naidoo, A Noorbhai, V Raghubar, J Reddy, A Singh, D Skinner, M Smith, B Singh; Inkosi Albert Luthuli Central Hospital: S Adam, C Alphonsus, Y Ameer, F Anderson, S Basanth, S Bechan, C Bhula, B M Biccard ${ }^{\star}$, T Biyase, J Bruce, I Buccimazza, J Cardosa, C Y Chen, B Daya, L Drummond, A Elabib, E H Abdel Goad, I E Goga, R Goga, T C Hardcastle, R Harrichandparsad, R E Hodgson, J Jordaan, N Kalafatis, C Kampik, A T Landers, E Loots, R Madansein, A Madaree, T E Madiba, V T Manzini, M Mbuyisa, R Moodley, M Msomi, D J J Muckart, I Mukama, D Naidoo, R Naidoo, T K Naidu, S Ntloko, E Padayachee, L Padayachee, M Phaff, B Pillay, D Pillay, L Pillay, A Ramnarain, S R Ramphal, P Ryan, A Saloojee, M Sebitloane, N Sigcu, J Taylor, A Torborg, L Visser; Ladysmith Hospital: I Asmal, M Gasa, G Madombwe*, S Mohanadasan; Lower Umfolozi District War Memorial Hospital: Y Bwambale ${ }^{\star}, \mathrm{N}$ Mayat, L Mlambo-Williams; Madadeni and Newcastle hospitals: S Cheddie, A Elghobasy, R Hurley*, M Kopieniak, NM Naidoo; Mahatma Gandhi Hospital: M Ahmed, N Amod, M B Greenwood, B Hira, D Kesene, K Laubscher, D Naidoo, N A Mahomedy, S Moosa, V Moonsamy, S Reddy, D Rungan*, A S Sader, A Thotharam; Ngwelezane Hospital: R Misra, M Naidoo, Y Selibean, S Sewpersad*, S Sham, J Wessels; Northdale Hospital: K A Adu, J T Liphaphang, D Maiwaid*, M Marais, T Mniki; Port Shepstone Hospital: C Africander, T Bejia, S Blakemore*, M Botes, B Bunwarie, C B Hernandez, M A A Jeeraz, D Legutko, A Lopez, J de Meyer, T Muzenda, N Naidoo*, M Patel, H Pentela, M Junge, N Mansoor, L Rademan, P Scislowski, I Seedat, $B$ van den Berg, D van der Merwe, S van Wyk; Prince Mshiyeni Hospital: K Govender*, D Naicker, R Ramjee, M Saley; R K Khan Hospital: A Ganesh, A Gounden, C Houston, S Mould, K Naidoo, A Nansook, N Rorke*, S Tarr; St Aidan's Hospital: T Ramsamy; Stanger Hospital: W Kuhn, R Matos-Puig*, Z Moolla*.

Limpopo Province. Pietersburg Provincial Hospital: M A Baloyi, L Bashiya, A Bogoslovskiy, M I Diale, N Escober, M E Gonzalez, D Horzstynski, P K Legodi, M E Maboya, R K Maila, A Z Machowski,
M V Mashile, O R Masia, J N Masipa, M S L Masotja, R Mavhungu, M S Mokoena, T Mukwevho, S Z Mzezewa, E V Neluheni, D S Nesengani, S Omoding, L O Orjiako, N Perez, S S Pillay*, M Rambau, R Ramos, H Raura, B Ryabchiy, T O Sadiki, M D Seshibe, O S Taran, E N Thwala, B Woldu.

Mpumalanga Province. Rob Ferreira Hospital: C Chikwiri, C A Cumbi, M Dalton, N P Godi, S B Ibirogba, P R Jujuju*, N R Mahlalela, F A Steyn, A J Troskie, J Vosloo.

North West Province. Job Shimankana Tabane Hospital: T D Kibibi, A J M Lubamba, S J Moumakoe*, K Pege, W Seboni.

Northern Cape Province. Kimberley Hospital Complex: P Anderson, A Conradie, M de Swardt* , M de Villiers, J Eikman, R Liebenberg, J Mouton, A Paton, L van der Merwe, C Wilscott-Davids.

Western Cape Province. Eerste River Hospital: H Maharaj ${ }^{*}$, C Strauss; George Provincial Hospital: D Tait, M Jordaan*; Groote Schuur Hospital: K Bergh, M E Casey, E Cloete*, R Dyer, S Jeffrey, D Khan, W Makhambeni, D C Nolte, G Picken, J Swanevelder, D Visu; Helderberg and Karl Bremer hospitals: M Jaworska*; Khayelitsha District Hospital: H Lalkhen, H Maharaj ${ }^{\star}$, S Serfontein; Mitchells Plain Hospital: T Biesman-Simons, S Carolissen, S Erasmus, J Holm, L Hoole, J Roos*, R Sauls, I Slabber, J van Schoor; Paarl Hospital: G Davies*, V Koller; Somerset Hospital: A Reed*, H Steinhaus; Tygerberg Hospital: I Conradie ${ }^{\star}, \mathrm{R}$ Dannatt, $\mathrm{M}$ du Plessis, L du Preez, K du Toit, C Fourie, C Gildenhuys, A Gretschel, Y Loots, P Marwick, Y Ngcwama, R Rautenbach, P Scheepers, N Terblanche, F H van der Merwe, R van Rensburg, A Vermeulen, S Vlok, S Watcham; Victoria Hospital: N Fuller*; Worcester Hospital: W Christian, R Duvenage, T Franken, G Gobetz, W Hansen, T Kambarami*, M Kok, J Janse van Vuuren.

${ }^{\star}$ Lead hospital investigator. 